\title{
13. A Design for Learning? A Case Study of the Hidden Costs of Curriculum and Organisational Change
}

\author{
Diane Kirkby and Kerreen Reiger
}

Like the sector itself, the study of higher education has expanded exponentially in recent decades. There are now many scholarly accounts of the impact of neoliberal and post-neoliberal policies on teaching and learning practices in universities internationally, and of the managerialist forms of governance accompanying them (e.g. Blackmore and Candiko 2012; Lorenz 2012; Blackmore et al. 2010; Olssen and Peters 2005; Slaughter and Rhoades 2004; Marginson and Considine 2000). There has, however, been relatively little theoretical and empirical work which builds on critical scholarship in comparable fields and, other than identifiably feminist scholars (e.g. Thornton 2011; Blackmore 2005; Evans 2004; Kenway et al. 1994/2006), few bring a consistent gender lens to analysis of the impact of neoliberal managerialism on universities. Analysis of workplaces in non-academic organisations, such as hospitals and other organisations, shows how complex patterns (of gender and cultural diversity, as well as of class) shape identities and interactions at the local levels of social practice and policy implementation (e.g. Connell et al. 2009; Halford and Leonard 2001). Management scholars in particular have demonstrated that building social trust and relationships is central to institutional success, including in higher education (Vidovich and Currie 2010; Tierney 2008; Gilson 2003). As hegemonic forms of masculinity in the public world have meant that women traditionally carried much of this 'hidden work' in organisations (Reiger 1993; Pringle 1998), it is, we contend, essential to study how implementation of neoliberal change initiatives impacts on the social relations and trust processes operating in specific institutional settings. 
Accordingly, in the first section of this chapter, we establish an interdisciplinary framework for understanding the relevance of trust and relational networking for productive academic workplaces, and then, in the second part, use it to assess the impact of recent organisational change in one university workplace. We argue that not only are traditional forms of collegiality in universities now threatened, but that recent managerialist reforms risk damaging the taken-forgranted relational work which makes them 'successful, productive enterprises', even as understood within an economic paradigm - those making optimal use of the skills of a diverse and equitable workforce to provide effective services to their 'customers'. So-called reform of 'knowledge work' that is driven 'top-down' by managers with little appreciation of complex, and gendered, organisational dynamics, we conclude, poses a risk to the very creativity and critical thinking still acknowledged as being central to a university's purpose (e.g. Universities Australia 2012). It actually undermines proclaimed university objectives such as those articulated in La Trobe University's 2012 'Future Ready' Strategy - 'the advancement of knowledge for the public good'; giving students an 'identifiably modern, globally relevant education' allowing them 'to be successful and to make the world a better place'; and offering staff the capacity for 'risk-taking, creativity and innovation in teaching and research' (La Trobe University (LTU) 2012).

\section{Universities under fire}

Accounts of contemporary universities point to the transformative political, economic and technological forces driving the international 'reform' assault on institutions of higher education - commonly seen by critics as the 'neoliberalist marketisation' of higher education. While not all agree with commentators still nostalgic for a past in which 'older white men' largely ran universities, or in which students' academic pursuits were accompanied by political and cultural endeavours (e.g. Hil 2012), there is considerable consensus on the largely negative impact of politically motivated demands for increased 'production' and improved educational 'performance'. Despite differences of emphasis, the extensive international higher education literature is largely pessimistic, frustrated and often very angry about these developments (Lorenz 2012; Marginson 2012; Wildavski et al. 2011; Zipin 2010; Wildavski and Slee 2010; Davies 2005; Kenway et al. 1994/2006; Readings 1996). Irish academic John Harpur, for example, has argued that we are now seeing an insistence on 'changing both the cultural and organisational ontologies of universities'. In what he terms this 'new alchemy' (Harpur 2010, 21), a narrative is being constructed and disseminated about universities as 'knowledge management' companies: 'economic return, entrepreneurship and innovation, knowledge delivery and scholarship are braided together' in a 'happy-ever-after' account of the future, one which he acknowledges has a 'powerful pull on the human 
imagination'. As Western policymakers grapple with the shifts in global power, higher education is coming to be seen as too important to be left to academics. Instead, 'belief in brainpower ... is [seen as] the last natural resource that the west has at its disposal' $(2010,13)$. Others are concerned about the resulting commercialisation of scientific research, especially of biotechnologies, and the liberalisation of commercial access to university research findings (Mowery and Sampat 2005).

Increased managerial control over academic labour is reported to be producing loss of professional autonomy and deteriorating working conditions for Australian as for British academics (Fredman and Doughney 2012; Blackmore et al. 2010; Anderson 2006; Evans 2004; Davies 2005). The result appears to be a culture of increasing acquiescence to intensified management demands, of diminished trust and widespread demoralisation and bullying (Zipin 2010; Vidovich and Slee 2009; Zabrodska 2011). Most worryingly, although the problems resulting from twenty-five years of efforts to transform or 'reform' higher education are now well documented, they remain completely sidelined or ignored at the policy level (e.g. Universities Australia 2012; Bradley et al. 2008). Few decision-makers are paying any attention to scholars' concerns, and, importantly, the general community has not been engaged in meaningful debate about the purpose and value of higher education. This shortcoming was brought home forcefully in the La Trobe experience of organisational 'reform' undertaken in 2012.

\section{Making invisible work count: Trust, emotional labour, and leadership}

Questions of institutional trust have been major focus of debate in organisational studies for some years (Kramer and Tyler 1996), especially 'the many ways in which individuals, organizations, and societies benefit from high levels of trust - and pay a steep price for its absence' (Kramer and Pittinsky 2012, Intro.). Gilson (2003), for example, analyses health care institutions as comprising 'a complex web of relationships' in which trust plays a central role at many levels (Gilson 2003, 1,463), and Tierney $(2006,2008)$ has examined the varying systems of trust shaping US universities. He concludes that 'a culture where trust is embedded in the organization's fabric is likely to be better prepared for dealing with the myriad problems that exist on the horizon than those institutions that reach for bureaucratic and hierarchical solutions' (Tierney 2008, 40). This is especially the case for highly trained, specialised workers such as the research scientists studied by Sitkin and Stickel (1996), who found managers imposing a 'total quality management regime' had no grasp of the nature of their work. In line with organisational studies which show that distrust and even revenge not only undermine morale but sabotage reform, it is precisely the destruction 
of trust and mutuality in social relationships that is central to critiques of the managerialist transformation of educational institutions (Vidovich and Currie 2010; Avis 2003).

It is trust and the emotional dimensions of academic work cultures, however, which are reportedly suffering: as Bronwyn Davies $(2005,7)$ puts it 'neoliberalese' has 'inserted itself into the hearts and minds of academics'. She and others have noted with alarm the deteriorating collegiality and increase in incivility and outright bullying amongst academic colleagues (Anderson 2006). Building on the insights of international critics of neoliberal pressures on universities, Lew Zipin (2010) offers a troubling and deeply troubled account of the emotional fate of those within the universities in our present 'post/late modern' dark times. Keeping people in line in accord with an increasingly punitive audit culture requires an increasing array of managers to oversee compliance and indeed to break the resistance to managerial directives of those accustomed to traditional professional autonomy. He argues that this results in 'undercurrents of pedagogically violent intent' and the danger of increased bureaucratic demands producing less flexibility and innovative thinking (Zipin 2010, 156-7; see also Reiger, Schofield and Peters 2015).

Discussion of academic leadership has also therefore taken on new significance with regard to managing the changes in contemporary universities (Morley 2012; Scott 2008). What is the effect on the academic workplace when the style of leadership that wins followers through moral authority and influence is replaced by imposing compliance through managerialist positional authority? A corollary to that question concerns the qualities of those rising to positions of leadership in the new corporate university - or as Morley puts it, 'who self-identifies and is identified to existing power elites as having leadership legitimacy?' (Morley 2013b, 118). Like others in management studies (e.g. Kotter 2002; Stacey 2010; Stacey and Griffin 2005; Scott 2008, 11) places particular emphasis on relational capabilities in leaders: the 'emotional and cognitive capacity to figure out when to draw upon specific competencies, and the capacity to learn from experience', arguing that 'those institutions that manage the growing change pressures best' ensure they develop and support effective leaders. The role of leadership is particularly pertinent when it comes to the question of how to attain gender equity and diversity. As US social scientist Phillipa Strum (1989, 221) has succinctly summarised it: 'Equality is not a natural phenomenon: it comes into existence only when a leader is present to guide society toward it. Yet reports suggest that an aggressive, punitive even 'muscular' style of leadership is being fostered in 'post-late' times universities, one widely discussed in the literature on new public management and on the 'masculinisation' of managerial cultures (Hearn and Parkin 2001; Wacjman 1999). 
Somewhat ironically in view of the attempt to make the public sector emulate the corporate world, there seems to be little engagement with alternative perspectives on leadership advanced by advocates of 'bottom-up' consultation and effective change management, including those who are recognised and respected in the private sector (e.g. Hoffer Gittell 2009; Kotter and Cohen 2002). In research on high-performing companies like some hospitals or aviation exemplars such as South West Airlines (Bamber et al. 2009), key factors in success include: improving coordination across parts of the organisation, seeking solutions from frontline workers; treating people with respect and emphasising courtesy both towards clients/customers and employees. Several corporate changemanagement frameworks stress the importance of organisational cultures and 'sense-making' (Weick 1995) and of skilled, facilitative leadership and engaging employees' emotions (Kotter and Cohen 2002). In their varying ways, they call attention to the centrality of mutual trust and respect, of understanding complex work cultures and of effective leadership of change (Kramer and Pittinsky 2012). Importantly, they offer a markedly different way forward from the management model currently dominating universities. Indeed, they are being employed in higher education in some cases (Tierney 2006; Blackmore and Candiko 2012). As Tsui (2012) reports concerning a major reshaping of curriculum at the University of Hong Kong, the process was not just 'top-down' but widely debated and contested. Eventually, agreement was reached on the flexible curriculum and student-centred approaches needed to prepare students for contemporary challenges as citizens. Even an OECD report on higher education (HE) noted that 'The experience of countries participating in the review suggests that mechanisms of regular and institutionalised consultation - which are inherent to consensual policymaking - contribute to the development of trust among parties' $(2008,317)$. What happens, however, when an institution lacks the required leadership and effective process?

A range of feminist accounts has demonstrated that more than what Connell (2006) terms a 'categorical' approach to gender - one based merely on women and men as numerical categories - is required to make sense of how institutions operate. Forms of knowledge and practice in higher education, as in society in general, reflect deeply held assumptions about what Butler (1993) terms 'doing gender', that is as a social practice performed in personal and public life. Power relations that privilege masculinity continue to shape patterns of social inclusion/exclusion, in close and fluid intersections with inequalities and identities associated with class, 'race'/ethnicity, sexualities and dis/abilities. From the extensive scholarship on gendered workplaces and social relationships produced in recent decades (e.g. Acker 1990, 2012; Adkins 1995; Halford and Leonard 2001; Wajcman 1999), we have ample evidence of the complexity of the gendered social relations of paid workplaces as well as of households. The importance of women's invisible labour has been widely documented, 
including emotional labour undertaken by those in service sector roles, such as flight attendants, along with the challenges women face in seeking equity in paid jobs and to avoid being squashed by the 'work/care' collision (Pocock 2003) presented by family demands. In terms of universities, Morley (2013b) describes the patterns whereby women's presence in universities has risen, both as academics and students, and explores why they nonetheless continue to be under-represented in university leadership positions. Similarly, Ross-Smith et al. (2005) report interviews with senior women in academia, as well as in business, which point to the challenges for women of being in 'not doable jobs'.

Evans goes further than the 'depressing tables of how many women are vicechancellors' to consider the politics of gendered knowledge. She argues that even the ideal student of the corporate university is an 'essentially female subject', one who conforms nicely to requirements of the audit culture $(2004,89)$; that deeply gendered forms of knowledge remain embedded in the academy; and most significant of all, that a mere pretence of institutional gender neutrality is internalised by many women as well as men $(2004,97)$. She insists $(2004,102)$ that gendered power and difference still matter, not in essentialist ways but that the real prejudices and disadvantages faced by women remain both structural and symbolic:

[S]tructural in the sense that women are included in a debased, but more demanding, form of academic life without any of the traditional support systems of men; symbolic in that the apparent erosion of gender difference disallows the investigation of that difference and the radical discussion ... which might result.

Evans' warning resonates with several concerns of other feminist scholars.

Many have pointed to the lack of social recognition accorded in paid workplaces, as in the home, to the relational and emotional labour commonly undertaken by women, whether as wives, secretaries or service sector workers (e.g. Adkins 1995; Pringle 1998). Several years ago Marilyn Waring's influential Counting for Nothing established the argument that the entire system of modern economics, systematised in the international accounting system, ignored questions of real human and environmental value: the dominant economic system, she argued, made no sense (Waring 1988). Similarly, feminist economist Nancy Folbre (2001), has argued powerfully that mainstream economics lacks any appreciation of the complex ways in which Adam Smith's 'invisible hand of the market' can only operate because it is underpinned by the 'invisible heart' of unrecognised and unvalued care labour. Though sometimes lacking this critical structural lens, attention to informal, interactional dynamics has increased in workplace studies, including research into the personal and financial costs of bullying and vindictive behaviours (Pearson and Porath 2005). Both the critical literature on the politically and economically driven transformation of contemporary 
universities, and other accounts of effective change management, point to the significance of social relationships in the academic workplace, and hence the need for detailed exploration of local organisational cultures and practices. It is no longer adequate, if it ever was, to conceptualise 'neoliberal reform' only as a linear, rational and managerially driven process. Each higher education institution is responding in distinct ways to the changes being imposed across the sector. As we will now argue, the La Trobe experience demonstrates how messy and complex the outcomes can be.

\section{The La Trobe University Faculty of Humanities and Social Sciences (FHUSS) Organisational Implementation Strategy (OCIS)}

There is not space here to provide a full account of the context and detail of the restructuring processes associated with the 2011-12 implementation of the FHUSS OCIS. In view of our stress on context, leadership and complexity of processes and outcomes, some background to our investigation of its impact on staff is necessary. Drawing students from the northern, less privileged, ethnically diverse areas of Melbourne and, in recent years, from rural campuses in Victoria's north, La Trobe has been proud of its long tradition of commitment to social equity and community engagement: for example, as the first local university to enrol applicants without Year 12 accreditation, notably women - a legacy still emphasised by La Trobe vice-chancellors. As some of our LTU colleagues have commented in recent years, La Trobe came late to the audit culture and 'new times' in HE. Protected through the 1990s-early 2000s, but also made vulnerable by a traditional collegial regime and senior leadership turnover, more than one wave of voluntary redundancies (in 2002 and 2006) was undertaken. Although these were difficult, they were not overly traumatic for most Humanities and Social Sciences staff, with several taking early retirement. In another faculty, however, the impact was severe, especially for critical feminist scholarship (Thornton 2006). The academic community was soon confronted by even sterner warnings about the radical changes needed in curriculum, finance and structures. As one academic commented (Interview, November 2012):

La Trobe's problem is that from about 2006 to now they've tried to do a technological revolution - all the IT systems, a major overhaul of all the management systems, and they've tried to introduce more recently, a teaching and learning revolution. It was like a parody of Trotsky's permanent revolutions, [but] the only one occurring was inside the university! And, can I say it, all the fuck-ups in the world occurred because you can't do it. 
The implementation of an across university 'Design for Learning' (DfL) initiative sought to streamline curriculum within degrees and, most importantly, to implement new forms of accountability directed at 'measurable outcomes'. Many committed teachers were supportive of such 'quality improvement' initiatives and devoted a great deal of (often unpaid) time to their implementation, while others resisted, resenting the imposition on their professional autonomy. Reorganisation of teaching was needed and subsequent new appointments, especially those designed for 'generational renewal' offered new opportunities. However, with new senior managers, and a new faculty management team in 2010, different systems and orientation produced tighter managerial authority and a decline in collegiality such as input into regular faculty and school board meetings.

By 2011, escalating concerns about the faculty's financial situation were further triggered by an apparent decline in enrolments and the impending governmentdriven open market in higher education. An external consultant undertook a 'review' of the faculty in mid-2011, producing reports which were widely regarded as seriously lacking in understanding of the disciplines in the faculty or the relationship between them, weak or no evidence for claims made, hence lack of transparency and bias and overall intensely negative tone. As submissions to the faculty concerning the Irvine Review made clear, destruction of trust was already under way. The subsequent organisational change process was being discussed in meetings called in early 2012 but was then fully presented as OCIS in June 2012, bringing to the fore simmering tensions and serious concerns about the processes involved and lack of understanding of the impact of planned changes. This OCIS stage 1 was then followed in September by OCIS 2, which followed industrial disputation and resort to Fair Work Australia. OCIS 2 introduced a new level of confusion and struggle by nominating, seemingly quite arbitrarily, the desired staffing profiles for each teaching (i.e. disciplinary) program and a designated process for 'matching' academic and some administrative staff to positions, and hence matching the required redundancies in 'affected' areas.

As external commentators Bode and Dale (2012) have provided a valuable detailed critique of OCIS in its broader context, one which resonated with the LTU staff who read it and accords with our reading of the documentary evidence, we will use and extend its analysis it here. They deconstruct the slides of meaning in the OCIS texts through which university structures are reinterpreted through 'a narrative of separation, internal division and unification', so that 'the university' becomes senior management and it is left unstated just what the disciplines and programs are if not part of 'the university'. Where 'the faculty' fits is subject to a further slide insofar as it becomes largely responsible for its own fate in inadequately supporting 'the university' financially. Bode and Dale note that in seeking to answer what the university 'is', the OCIS positions the 
faculty both as actor and its management as victim of circumstances, yet the authors of the document are not named and the passive voice camouflages any possibility of responsibility. In terms of curriculum planning, similarly, Bode and Dale astutely note ambivalence about disciplines and the separation of academic staff from planning of teaching and learning, and from the entity called 'the faculty'. Most ironically in view of the external pressures, they also point to the seemingly 'baffling lack of interest in - or at least, of detailed attention to - the nature of "the market"': students too are outside the 'university' as consumers, whose shifty allegiances occasion considerable anxiety, but little, it seems, effective research and analysis (Bode and Dale 2012).

\section{Exploring the impact of the OCIS}

Our analysis here is based on qualitative evidence from approximately 50 teaching, research and administrative staff in the Faculty of Humanities and Social Science (HuSS). In late 2012, we sent an email message around the faculty inviting people who wished to speak with either or both of us to get in touch and assured complete confidentiality. Some interviews and discussions were undertaken by Kerreen Reiger in the role of 'insider-outsider' critical friend for use as material for a planned publication on innovation in universities (Reiger, Schofield and Peters 2014, in press). Diane Kirkby's involvement was in accord with the EO Committee (for Equality Diversity and Wellbeing)'s terms of reference, viz: 'to ensure staff and students work in an environment free from harassment and discrimination' and 'to monitor and report ... on the implementation of the university's Equal Opportunity for Women in the Workplace (EOWW) Strategic Plan'. Motivation for the investigation was informed by discussions over working conditions which had been taking place in an informal women's network since it first began meeting in 2010 amid growing concerns over the direction of the faculty, managing the work-family balance and of the handling of some specific instances of sexual harassment and assault. The OCIS process raised serious concerns among this group, especially when specific areas like Gender Sexuality and Diversity Studies and Art History were targeted for cuts, despite being financially successful and having a rising level of enrolments. The implications for women staff and for the possibilities of maintaining and growing feminist theory and knowledge (Morley 2013b) were too stark to be ignored.

In informal and semi-structured conversations, some recorded, and email exchanges with staff across the faculty, together or singly, we consulted with a range of our colleagues, first always gaining their permission, which was often enthusiastically given, to listen to 'their story'. Those who came forward were staff on both regional and metropolitan campuses, those formally deemed 
'affected' by staff cuts and also 'unaffected' staff, women and men, researchonly and teaching staff, those who took voluntary redundancies, those whose redundancy was involuntary, those who were matched to remaining positions, senior and junior staff, program coordinators, postgraduate students, and senior managers. In corridor chats as well as through participant observation in meetings at varying levels but especially through the data through which we were privileged to gain personal accounts, we found a depth of grief and depression among the staff that is consistent with what Zipin (2010) has described as the dark side of managerialism: a consequence of managerial efforts to break academic power and spirit. Although we sought to ensure that a range of views was represented, no one came forward to offer any real defence of the OCIS or of current governance of either the Faculty or the University. In the following discussion we focus on three issues, the overtly gendered implications, criticism of poor processes and (masculinist) leadership, and the resulting emotional damage and impact on work cultures and social relationships, some of which fell most heavily on women, including administrative staff.

\section{Identifying gender dynamics at work}

The OCIS experience revealed the difficulty of rendering gender dynamics visible as a social process which clearly involves more than simply the relative positions of women and men. It brought home the shortcomings of an EOWW policy that has no allowance for the complexity of gender dynamics interwoven in institutional decision-making or the social and especially trust relationships central to workplace and disciplinary cultures. Nevertheless, there are times when relative numbers of women to men are important. In relation to the consideration of redundancies and the process by which those decisions would be made, requests by staff for information on the processes to be followed did not indicate any awareness of ensuring effective gender equity. This was partly a shortcoming of an EOWW policy which is based on numerical representations of women vis-à-vis men as the measurement of institutional success. When the redundancies (voluntary and involuntary) were announced, the numbers of men to women were equal but this statistical equality was not consistent with the proportion of male to female staff in the faculty, where women outnumber men. It did not allow for variations across disciplinary, geographic or age areas. While it is not clear if a disproportionate percentage of women or men were among the 'affected' staff, it seems more men were retained in key curriculum areas identified for future development, more women were retained on regional campuses where the future is still uncertain, more men were among the younger and more women among the junior levels. Although the term 'relative to 
opportunity' was included as a relevant criterion, there was no evidence of design or forethought concerning how the numbers were achieved and can be maintained, nor of attention being paid to future mentoring/leadership needs.

Not surprisingly, responses to the OCIS reflected common gendered life patterns and expectations. Both men and women volunteered to take voluntary redundancy, but some women chose to do so because of the increasing difficulties of maintaining their family responsibilities within a perceptibly (and rapidly accelerating) deterioration of a 'family-friendly' workplace. In interviews and informal conversations men tended to emphasise the financial incentives that were offered to go, while many women stressed their responsibilities towards family, colleagues and students. Women spoke of 'a culture of expectation making it very difficult', the 'lack of flexibility' and no options for making it easier to maintain a level of productivity and of their anticipation that in the reduced faculty staffing, increased teaching workloads would accelerate a decline of conditions. Some women found the balancing act now 'just too hard'. Others reported discouragement and disincentives being placed in their path, and sometimes overt discrimination by senior men, as causes in their decisionmaking; that maternity leave had been treated as 'complicating' their careers, and a barrier to their promotion, a reason not to apply for external grant funding. Of the men who went voluntarily, some apparently did so out of a willingness to retire or a preference to take a risk on starting a new career or relocate to another institution rather than stay in what they described as a poorly-managed workplace where disillusionment prevails and the future looks bleak. Some women saved their jobs by indicating their willingness to job-share with their colleagues. One program saved jobs by three women negotiating collaboratively to take a significantly reduced fraction of employment. However, other women who indicated their willingness to go part-time were instead offered involuntary redundancy, raising the prospect they had made themselves vulnerable. Some observed that senior women had been treated very badly within the changing culture, thus proscribing their own aspirations or modifying their behaviour. They were given the impression that seniority was no guarantee of respectful treatment for women and no protection from losing their jobs.

Although the final cuts were in the end a little different, the curriculum areas first announced to be excised by the OCIS had all or largely female staff, and were areas where diversity was most concentrated. Of particular concern was how OCIS devalued gender-and-diversity research and teaching in the curriculum at the expense of areas employing men (e.g. sports journalism). As a successful area, one of importance to a university priding itself on its diversity and radical identity to attract students, one might assume that the Gender, Sexuality and Diversity Studies (GSDS) program would be promoted as a key interdisciplinary area vital to contemporary global challenges. Not so. While the coordinator of 
GSDS was eventually saved after a major community surge of support, it was at great cost to its coordinator and to the then truncated program. Assurances that 'People who were regarded as having strategic value to the future of the University were not accepted' for redundancies, did not apply to a staff member teaching a core subject in GSDS, and an active researcher in the field of sexual and family violence. Thus the gendered assessment of 'what counts' shaped the processes in complex ways, and to other aspects of such dynamics we now turn.

\section{Processes and leadership issues}

As recounted to us, many responses to the OCIS were overwhelmingly critical, and surprisingly united in expressing anger at the ineptitude, confusion and frustration that the process entailed. Recurrent themes in interviews included the absence of respect for and trust of staff, of meaningful rather than 'techno'communication, and the damaging impact of the negative tone in which much information was conveyed and meetings conducted, as well as the silence with which staff communications were greeted. One commented that emails were often sent from faculty management after 5pm, often on Fridays, as though this 'was an intended plan to give them important information when people were not together' to discuss and respond. Accordingly, there was a significant decline in essential institutional trust: '[T]here was more fight in people early on, but we later lost the fight, as though it was strategically engineered information leading to people becoming demoralised, so eventually we did not really know if the financial crisis was real or manufactured' (interview, November 2012).

There was criticism of the management's over-reliance on outside experts and legal advisers, an approach which also appeared to be a defensive strategy showing lack of respect for, and ignoring the experience, expertise, knowledge and goodwill existing within the faculty. It set up, or perhaps was instigated by, increased distance that was maintained throughout the process between academic and many administrative staff and management. Other forms of division intensified. In view of the loose networked character of universities (Bento 2013; Blackmore and Candiko 2012), change processes do not work in rational, linear and predictable ways. In this case, internal conflicts between previously harmonious disciplinary groups such as Sociology and Anthropology, and between rural and city colleagues were fostered, damaging collegiality although the projected curriculum developments, notably redevelopment of the BA, actually required enhanced collaboration across fields. Moreover, for those on the ground, said one program convenor, 'there was no thought about how we might have to manage it, and it was like a war zone'. Another recounted 'waking up at night and worrying about Bendigo [campus]', saying that the ways the 'indicative structures' were imposed was 'just appalling'. 
Concerns about lack of effective senior leadership and lack of accountability at that level were pervasive: 'there was no one player and no overall vision', as one academic said. There was a widespread sense of confusion as 'to who was ultimately responsible' especially as the VC was new to the job; so 'any resistance from below was floating up and going into space' and people felt that those "up the "top"' could do anything they wanted', said another informant. These concerns were exacerbated by the gendered dynamics involved in the changes to the culture and to the power structure within the faculty which went hand-in-hand with the perception of a 'highly personalised process that people were going not because of their record but because of who was in their corner'. Although women outnumber men in the faculty, there has been a loss of women from faculty management positions (Head and Deputy Heads of School, Associate Deans, Deputy Dean) and their replacement by men, which has led to a concentration of men in positions of authority and power, and a loss of leadership opportunities for women. Another program convenor said that respect was missing, especially for women, and that the faculty leadership seemed to have 'a fiefdom here'.

Those promoted seemed to be 'yes-men or -women', according to several of those interviewed, people who would 'not rock the boat', said some administrative staff. Furthermore, 'the university did not seem to have a diversity principle', unlike many private-sector boards. Instead, there was 'a certain element of a boys' club, both at faculty and university level ... in effect all like-minded people', which can be useful, but 'in terms of effectiveness is not so ... it leads to "uncritical support"'. Greater diversity, both ethnic and gender is needed. It seemed that leadership has become more hierarchical, 'running it like the Army' rather than expecting responsible school and program-level colleagues to participate effectively in decision-making. The example of a senior assertive woman being marginalised and pushed out left a lesson for others; as one said, 'I therefore won't be as loud politically, as a senior female can't operate like that in this environment. I'll have to exercise judgment on when to be assertive.' Another said there are 'double messages when reporting sex harassment and bullying. "Yes we care", and "don't make trouble for the organisation"". Women staff thus expressed feelings of unease at the apparent empowerment of masculinity they have observed in the corridors and meeting rooms. They face the troubling issue of whether there is a role for senior women in the new managerial university: 'There used to be transparency in getting into managerial structures of the Faculty. That is no longer the case.' Staff, especially women, who asked hard questions such as wanting detailed financial evidence, were characterised as difficult personalities resistant to change, rather than as trusted employees exercising their critical expertise in the faculty's interest. 


\section{Grief, loss and suppression of dissent}

In light of debate about the declining capacity for opposition to managerialist imperatives (Lorenz 2012; Davies 2005), the experience of La Trobe HuSS staff suggests this occurred through complex and, as Zipin (2010) suggests, emotionally troubling processes. A series of losses were mentioned often a fostering of ill-feeling, undermining of collegiality, loss of their capacity to recruit and work effectively with postgraduates, loss of valuable staff, and the loss of the reputation of HuSS Faculty seen to be important in the community, and in future competition for research grants and staff recruitment. Staff complained that the management saw academic staff as 'problems' and treated them accordingly. They asked why it was done this way. They were not alone. One reported being told by a consultant brought in to offer advice to those considering or taking redundancies, that he had never seen anything like the OCIS process in many years working in the field: he described his work for organisations as usually 'like using a clean scalpel to assist healing, but this was like it was being done with a rusty bread knife'. Many staff said they felt they had not been heard, and no one knew if anyone even read the many submissions they spent nights and weekends preparing. As no effective collegial support had been provided to them during the OCIS, in spite of 'counselling' opportunities for those directly affected, they welcomed the opportunity to speak to us and were grateful that we were listening.

Their stories revealed the devastating impact of the OCIS implementation on the morale and productivity of staff and postgraduate students, with undergraduates demonstrating, even violently. All reported experiencing unusual levels of stress and anxiety, with attendant physical symptoms of insomnia, disruption to their normal routines and personal relationships, and reduced professional performance. Some individuals sought medical treatment, or reported selfmedicating with alcohol. One, who rarely drank alcohol, reported astonishment that the bottle of whisky was suddenly gone after a week rather than a year, and feeling so stressed that family suffered, as well as teaching. Some feared their recovery would be very slow. Reflecting this sense of trauma, many staff who survived the redundancies are now speaking of feeling 'survivor guilt', and are pessimistic about the faculty's and the university's future. Not only academic staff felt the burden. We have been told that many faculty administrative staff, most but not all of whom are women, feel depressed and demoralised in the current regime, even months after the OCIS restructuring. They expressed concerns about the lack of transparency in appointment processes in the restructure yet, although they have been told 'it is not personal' and they are 'entitled to ask for information', that is contradicted because when someone queries processes, such as in a public forum, 'they are jumped on as being disloyal'. Genuine questioning of decision-making processes and effective recording of meetings 
for transparency and good governance is no longer seen as legitimate. As one colleague noted in an email follow-up to an interview, 'concern to maintain positional power' at senior levels meant:

that the people who do the work and have the knowledge and experience to come up with innovative solutions are disempowered and then blamed for the problems - e.g. out-of-date curriculum. There was enormous frustration that the innovative and critical strengths of people in the Faculty were not able to contribute to solving the problems.

The shift from flatter governance structures to top-down and positional power was both completely demoralising and counterproductive in the face of the very real external pressures on the university.

The emotional responses that our interviews disclosed could be (and were anticipated by management to be) expressions of opposition to change, a failure of staff to recognise the writing on the wall. By contrast, we argue it was a failure of senior and faculty management to understand the substantive issues and provide the necessary detailed evidence, not to mention coherent vision, to underpin change. Most importantly, as a subsequent external consultancy report articulated (KPMG 2013) effective leadership and change management were seriously inadequate. What staff at La Trobe resisted was not change per se, or even downsizing, which had happened before, but they sought supported opportunities for curriculum innovation and respectful collaboration that could underpin future viability. In spite of recognition of the external pressures on the university, the need for radical upheaval was experienced as arbitrary. Importantly, and especially galling for academics, it was not grounded in actual evidence of the productivity, potential and financial viability of particular units and programs. There was also little recognition of the distress, even devastation, caused by loss of a valued institutional culture, workplace environment and social relationships, all of which are built up in time and in 'place'.

The La Trobe FHuSS experience bears many of the hallmarks explored in studies of the restructuring of corporate workplaces (Kotter and Cohen 2002; McCabe 2007) but many are particular to the de-professionalisation of educational work (Fitzgerald 2009). In the case of LTU's OCIS, however, they were made much worse by bewildering contradictions within management's demands; inconsistent, ambiguous and shifting exercises of power; the differential and sometimes contradictory work experiences of both administrative and academic staff. Power and control infuse the strategies, innovations and technologies that managers employ, and these operate in both intended and unintended ways, but their overall impact can be to 'impoverish working life'. Many leaders of the corporate workplace, as McCabe $(2007,221)$ claims, 'lack the imagination, courage and empathy for others' needed to optimise the creativity and ingenuity 
of the workforce. As an astute interviewee observed in November 2012: 'Our faculty was the scapegoat, the guinea pigs for the experiment. Such waves of change are not going to stop and I think unless we can work out ways to survive, "brand ourselves" as they like to say, they'll keep coming back.'

Some staff reported trying to find ways to forge new working relationships with their colleagues, united in having shared a difficult, highly stressful experience. They point to the staff and La Trobe's highly diverse student body as the best hope for the future: 'There are a lot of talented people here which is the only reason this faculty still has credibility.' Others by contrast point to increased individual self-interest, keeping doors closed and still feeling vulnerable, even many months after the major impact of OCIS had passed. As one administrative staff member remarked recently, 'there is no trust left'.

\section{Conclusions}

The analysis we have offered in this chapter exposes the centrality of good leadership, trust in governance and high staff morale to an effective change process, one that is capable of sustaining a productive learning and research environment. Drivers of the OCIS process at La Trobe showed insufficient knowledge of organisational processes, of how the daily work of learning and teaching was achieved, or a grasp of the social relations that allowed the local workplace to function productively. The organisational restructure and associated curriculum and staffing changes did not prioritise staff knowledge or wellbeing, nor recognise the close correlation between those factors and success in moving people forward. Staff complained that the administration and management of the university saw academic staff as problems and accordingly treated them with distrust, rather than examining issues of competence of leadership and management practices at other levels of the faculty. Clearly too much change was attempted at once and several staff said that linking organisational restructuring to curriculum redesign was a major mistake. It became clear that the OCIS process undermined the good social relationships and productive work culture that had been a hallmark of the faculty and underpinned its reputation for scholarship. The experience of La Trobe HuSS staff suggests that the outcome of poorly managed change can be a high cost to the institution: fostering of illfeeling and resentment, the loss of capacity to recruit and retain postgraduates, the loss of respect by valuable staff and care for the reputation of the university in the community, which can impact on future competition for research grants and staff recruitment. The fear of extinction remains strong among humanities and social science staff who survived the 2012 cuts at La Trobe. The recovery process can be painfully slow and impede further initiatives. 
How to provide a new form of networked institution to allow the critical capacities of Humanities and Social Science scholars to flourish in new ways in a changing context is, to use complexity theory's premises, an 'emergent' possibility. The role of renewed disciplines and inter/trans-disciplinary fields, such as studies of peace/conflict, social and environmental sustainability, and gender and sexuality offer promising opportunities. These cannot be realised, however, if only narrow economic criteria and limited ideas of 'quality' dominate change efforts in higher education, and knowledge based on local institutional experience is demeaned. Notwithstanding the damning nature of critiques of neoliberalist assaults on the academy as 'killing thinking', to use Mary Evans' evocative and pessimistic term (2004), we need to seek out glimmers of contradiction and thus any grounds on which to base not merely resistance, but an alternative vision. In view of the major challenges of the 21 st century, the essential starting points of reform need to be, first, genuine commitment to the social as well as economic value of education, and, second, recognition of the importance to institutional success of fostering social trust, equitable relationships and effective leadership in university workplaces. 
This text is taken from Through a Glass Darkly: The Social Sciences Look at the Neoliberal University, edited by Margaret Thornton, first published 2014, this version 2015 by ANU Press, The Australian National University, Canberra, Australia. 